\title{
Development and validation of exercise rehabilitation program for cognitive function and activity of daily living improvement in mild dementia elderly
}

\author{
Mi-Ri Choi', Ji-Youn Kim², Eun-Surk Yi',* \\ 'Department of Exercise Rehabilitation \& Welfare, College of Health Science, Gachon University, Incheon, Korea \\ ${ }^{2}$ Exercise Rehabilitation Convergence Institute, Gachon University, Incheon, Korea
}

We investigated the effect of exercise rehabilitation based on fine motor movement for the elderly with mild dementia. Using electroencephalogram (EEG), the change of brain wave of them based on fine motor movement and comparing the improvement level of cognitive ability and performance capability in daily living activity was recorded. The subjects were the elderly with mild dementia living in a sanatorium in Incheon city. Mini-Mental Status Examination, activity of daily living $(A D L)$, and the influence on depression were examined. After 8-week

\section{INTRODUCTION}

Population ratio of the elderly over 65 in Korea is rapidly increasing, so population ratio of the elderly is expected to be over $20 \%$ in 2026 , which means super-aged society. It is expected to be $30 \%$ in 2037 and to be $40 \%$ in 2058, which forecasts the unprecedented increasing rate in the world (Statistics Korea, 2018). Dementia is the most typical senile disease, and medical fee of dementia patients has been continuously increasing staring from 2005 (Yoo and Kim, 2017). Dementia that shows the high increase of prevalence based on population aging is expected to increase to 1.27 million people in 2030 and 2.7 million people in 2050 (Ministry of Health \& Welfare, 2018) compared to 0.54 million people in 2012. Therefore, preventive approach and treatment for mild dementia have appeared as an important issue.

Measurement of brain wave is a noninvasive method that investigates the brain status in real time. Measurement of brain activation degree by brain wave is an effective, economic, and stable exercise program, significant difference in cognitive function and $A D L$ was observed, however, and there was no significant difference in depression. In the EEG, there was a significant difference in $\alpha$-wave. This study suggests the chance to remind the necessity of exercise programs for improving cognitive function and ADL of the elderly with dementia.

Keywords: Exercise rehabilitation program, Cognitive function, Activity of daily living, Depression, Electroencephalogram, Mild dementia
${ }^{*}$ Corresponding author: Eun-Surk Yi (iD https://orcid.org/0000-0002-9370-5231 Department of Exercise Rehabilitation \& Welfare, College of Health Science, Gachon University, 191 Hambangmoe-ro, Yeonsu-gu, Incheon 21936, Korea Tel: +82-32-820-4442, Fax: +82-32-820-4449, E-mail: Yies@gachon.ac.kr Received: March 4, 2018 / Accepted: April 5, 2018 tool before and after treatment (Grieder et al., 2016). Brain wave is classified into delta wave, theta wave, alpha wave, beta wave, and gamma wave based on frequency range. Alpha wave is classified into slow wave, which is less than $8 \mathrm{~Hz}$, and fast wave, which is more than $13 \mathrm{~Hz}$ (Brassen and Adler, 2003; Onofrj et al., 2003; Pugnetti et al., 2010). In most elderly with dementia, theta wave is regularly slow wave and it is noticeably increased in the old age. Alpha wave is a basis of brain wave, this wave tends to be decreased gradually when dementia is processed. Beta wave is a fast wave and it is observed when concentrating. Beta wave tends to be decreased gradually when dementia is processed, and this wave is influenced by emotional activity or physical exercise (Howard et al., 2003).

Regular exercise acts as a useful factor for dementia patients. Exercise activates cerebral metabolic activity, increases cerebral blood flow, and facilitates neural transmission (Okumiya et al., 1996). Exercise prevents injury by increasing elasticity of arterial wall (Oshida et al., 1989) and improves chronic diseases, such as 
osteoporosis, depression, and emotional stress (Han et al., 2010).

Although the effectiveness of exercise is widely known, more than $60 \%$ of the elderly are not regularly exercising, and most of elderly with dementia could not participate in regular exercise (van Alphen et al., 2016). If we look into living conditions of the elderly with mild dementia, $31.9 \%$ of the elderly have difficulty in daily life such as showering, putting clothes on, eating, walking, using restroom (Ministry of Health \& Welfare, 2018), so participating in exercise is difficult. If the cognitive function of the elderly is deteriorated, activity of daily living (ADL) becomes more difficult (Man et al., 2006). Therefore, development and application of exercise program for the elderly with mild dementia to improve their daily life is necessary.

As one of the methods to increase the effective performance in
ADL or cognitive function, improvement of fine motor movement is important part of education. Fine motor movement properly solves the problems related to basis of daily life activity such as eating, putting clothes on, showering, and using restroom. Therefore, we tried to verify the effect of exercise rehabilitation based on fine motor movement for the elderly with mild dementia by understanding the change of brain wave. We also compared the improvement of cognitive function and performance of ADL.

\section{MATERIALS AND METHODS}

For this study, Mini-Mental Status Examination (MMSE), ADL, and depression were examined. The change of electroen-

Table 1. Composition of exercise program for mild dementia

\begin{tabular}{|c|c|c|c|c|}
\hline Classification & Purpose & Exercise movement by step & Time period (wk) & Duration of time (min) \\
\hline \multirow[t]{6}{*}{ Warm-up exercise } & Stretching & Right and left extension of waist & $1-8$ & 5 \\
\hline & & Shoulders & & \\
\hline & & Elbows & & \\
\hline & & Fingers & & \\
\hline & & Pushing palm & & \\
\hline & & Tapping & & \\
\hline \multirow[t]{23}{*}{ Main Exercise } & Emotional exercise & Grabbing an object & $1-2$ & 25 \\
\hline & & Roll a tool with palm & $3-5$ & \\
\hline & & Roll a tool with sole of foot & & \\
\hline & & Moving arm by grabbing an object & $6-8$ & \\
\hline & Manipulative exercise & Shifting a ball right $\rightarrow$ left $\rightarrow$ right & $1-2$ & \\
\hline & & Grab a ball with two fingers & $3-5$ & \\
\hline & & Grab a ball after throwing it & & \\
\hline & & Roll a ball & $6-8$ & \\
\hline & & Exchange a ball with a partner & & \\
\hline & Coordination exercise & Push with a ring finger & $1-2$ & \\
\hline & & Move toes & & \\
\hline & & Make a diagonal pattern of both hands & $3-5$ & \\
\hline & & Rock-paper-scissors & & \\
\hline & & Make symmetry of rock-paper-scissors & $6-8$ & \\
\hline & & Crumple newspaper with hands & & \\
\hline & & Crumple newspaper with feet & & \\
\hline & Recreation & Throw balls into basin as many as possible & $1-2$ & \\
\hline & & Dart Play - throw a ball and hit a stood-up paper cup & & \\
\hline & & Relay-pile paper cups & $3-5$ & \\
\hline & & Move balls & & \\
\hline & & Hit an object by covering eyes with a towel & & \\
\hline & & Bowling play - roll a ball and hit a stood-up paper cup & $6-8$ & \\
\hline & & Drop-the-Handkerchief game & & \\
\hline \multirow[t]{2}{*}{ Cool down Exercise } & Stretching & Repetition of warm-up exercise & $1-8$ & 10 \\
\hline & & Talk about Today's Exercise & & \\
\hline
\end{tabular}


cephalogram (EEG) wave in frontal lobe of the elderly with mild dementia was also determined.

\section{Exercise program}

Exercise program of fine motor movement for the elderly with mild dementia is composed of stretching, main exercise, and cool down exercise. Main exercise is divided as emotional exercise, manipulative exercise, and coordination exercise. The level of difficulty by exercising time has three steps and the level was increased gradually. In addition, recreational contents and music were included. Detailed composition of program is shown in Table 1.

\section{Investigation targets}

Investigation targets of this study are the elderly with mild dementia living in a sanatorium in Incheon city and it's implemented for 20 elderly diagnosed with very mild or mild dementia from doctors. The elderly were those who experience cognitive and emotional disability recently and the range of mild dementia was set between MMSE in Korean version of the Consortium to Establish a Registry for Alzheimer's disease assessment packet (MMSE-KC) score 15 and 23. Intent and purpose of this study was explained to the chief of sanatorium in the area and cooperation was asked. Targets were the elderly in the organizations which allowed the study participation and the elderly themselves or caregivers of the elderly listened to the explanation of study's intent and agreed to participate by signing in a written form. Selection standard of research targets is shown in Table 2.

\section{Inspection criteria}

For targets who participated in survey, MMSE-KC, ADL, short form geriatric depression scale (Korean version of Short Form of Geriatric Depression Scale, SGDS-K), and sleep EEG were performed.

Table 2. Selection standard of research targets

\begin{tabular}{|c|c|}
\hline Criteria & Contents \\
\hline A & $\begin{array}{l}\text { The elderly at organizations that allow the research participation after } \\
\text { intent and purpose of study was explained to the chief of welfare fa- } \\
\text { cilities in Incheon Metropolitan City or in Dementia Care Center for the } \\
\text { elderly and cooperation was asked. }\end{array}$ \\
\hline B & $\begin{array}{l}\text { The elderly diagnosed with very mild or mild dementia from doctors and } \\
\text { the elderly who experience cognitive and emotional disability recently. }\end{array}$ \\
\hline C & $\begin{array}{l}\text { The elderly who are allowed to participate in the study and determined } \\
\text { to have good health status doctors at each organization. }\end{array}$ \\
\hline D & $\begin{array}{l}\text { Corresponding to } A, B, C \text { and agreement on a written form to participate } \\
\text { in the study after the elderly themselves or caregivers of them hear the } \\
\text { explanation on intent of research. }\end{array}$ \\
\hline
\end{tabular}

\section{Measuring tool for cognitive function}

To measure cognitive function, MMSE-KC was used. This tool was composed by considering the illiteracy rate of the elderly in domestic such as Jhoo et al. (2005). It is composed of criteria such as orientation about time and place (5 points each), instant recall (3 points), attention (5 points), delayed recall (3 points), language function (6 points), composition ability (1 point), and understanding and judgment (each 1 point). The range of points is from 0 to 30 and as the point gets higher, it means that the ability of cognitive function is higher. Combined score is determined based on gender, educational level, and age. Reliability of tool in this research was Cronbach $\alpha=0.80$.

\section{Measurement tool for performance ability of daily living activity}

For ADL, measuring tool by Ko et al. (2017) was used. This is to evaluate basic daily living activity for dementia patients and it evaluates the necessary activity to take care of the body and maintain it. It takes about 5-10 min and by considering the status of targets for the most recent month, it's performed by counseling with caregivers of the targets. Survey is composed of 24 points in total containing self-management/hygiene (12 points), walking ( 6 points), control of urine and feces ( 6 points). Detailed composition criteria including measurement contents is as follows in Table 3. When performing independently, the score was 0 . When there is a little of help, the score was 1 . When complete help is needed, the score was 2. As the score gets higher, it's interpreted that independent performance of ADL is difficult.

\section{Measuring tool of depression}

In order to measure the depression level of the elderly with dementia, SGDS-K was used (Bae and Cho, 2004). When it was developed, internal consistency was 0.88 and the credibility was recognized by being used variously in the clinic. This tool gives 0 to "yes" and 1 to "no," so the range of score is from 0 to 15 . It is interpreted that negative questions were converted reversely that as score gets higher, depression level is more serious. Credibility of

Table 3. Activity of daily living composition

\begin{tabular}{llc}
\hline Factor & \multicolumn{1}{c}{ Measurement contents } & $\begin{array}{c}\text { No. of } \\
\text { questions }\end{array}$ \\
\hline $\begin{array}{l}\text { Self-management/ } \\
\text { hygiene }\end{array}$ & $\begin{array}{l}\text { Face wash, brushing teeth, shampooing, } \\
\text { eating, putting clothes on, showering, } \\
\text { leaving alone, and wearing shoes } \\
\text { Moving, behavior and walking in the room, } \\
\text { walking up and down the stairs }\end{array}$ & 6 \\
Control of Urine and Feces & $\begin{array}{l}\text { Toilet training, using restroom and clean-up } \\
\text { Talk }\end{array}$ & 3
\end{tabular}


tool in this research was Cronbach $\alpha=0.87$.

\section{Measuring tool of brain wave}

In order to measure brain wave in this study, bluetooth wireless measuring instrument (neroNicle E2, LAXTHA, Seoul, Korea) was used. This is two-channel metal electrode wireless measurement tool which is band-type and nnE2 was used for measurement program. Because measurement of brain wave is very sensitive signal, targets and two researchers processed the measurement in an independent area excluded of noise and the place was prepared with appropriate temperature and humidity inside of sanatorium. During measurement, it was processed in front of a chair that has a back and a desk and when measuring the brain wave, it was measured in the status of eyes to be opened possibly. By minimizing the movement and sound, it was set not to measure the strange brain wave.

\section{Approaching method of data}

After entering the collected MMSE-KC, ADL, SGDS-K into a computer, by utilizing the original program of IBM SPSS Statistics ver. 21.0 (IBM Co., Armonk, NY, USA), average (mean \pm standard deviation) and standard deviation about all the factors were drawn according to purpose of data analysis. Data for brain wave was analyzed by utilizing fourier transform of MatLab program. For this analysis, paired $t$-test was performed and significance level was performed at $P<0.05$.

\section{RESULTS}

By developing exercise program for mild dementia, the difference before and after exercise program was verified as follows as a result of applying it for 8 weeks.

Results of cognitive function, performance capability of daily living activity, and depression score are shown in Table 4. In cognitive function, the score before performing exercise program was $18.85 \pm 2.18$ and the score was $19.90 \pm 2.31$ after performing ex-

Table 4. Change of cognitive function, performance capability of daily living activity, and depression

\begin{tabular}{lcccc}
\hline Variable & Before & After & $t$ & $P$-value \\
\hline Cognitive function & $18.85 \pm 2.18$ & $19.90 \pm 2.31$ & -3.269 & $0.004^{* *}$ \\
$\begin{array}{l}\text { Performance capability of daily } \\
\quad \text { living activity }\end{array}$ & $13.80 \pm 1.79$ & $15.75 \pm 1.33$ & -4.174 & $0.001^{* *}$ \\
$\begin{array}{l}\text { Depression level } \\
\text { P. }\end{array}$ & $8.95 \pm 2.09$ & $8.85 \pm 2.20$ & 0.357 & 0.725
\end{tabular}

Values are presented as mean \pm standard deviation.

${ }^{* *} P<0.01$. ercise program. It showed a statistically meaningful difference by performing the exercise program. In performance capability of daily living activity, the score was $13.80 \pm 1.79$ before performing exercise program and the score was $15.75 \pm 1.33$ after performing exercise program. It showed a statistically meaningful difference by performing the exercise program. In depression, there was no meaningful difference in before and after performing exercise program.

Results of score of $\theta$ wave, $\alpha$ wave, and $\beta$ wave are shown in Table 5. In Ch2 (position with sensor: $\mathrm{Fp} 2$ ) of $\theta$ wave, it was $0.2915 \pm 0.02870 \mu \mathrm{V}$ before performing the exercise program and it was $0.2715 \pm 0.02418 \mu \mathrm{V}$ after performing the program and significant difference was shown compared to before performing the program. In Ch1 (position with sensor: $\mathrm{Fp} 1$ ) of a wave, it was $0.2855 \pm 0.07911 \mu \mathrm{V}$ and it was $0.3075 \pm 0.06766 \mu \mathrm{V}$ after performing a program. In Ch2, it was $0.2915 \pm 0.075900 \mu \mathrm{V}$ before performing the exercise program and it was $0.3140 \pm 0.06785 \mu \mathrm{V}$ after performing the program and there was a significant difference compared to before performing the program in both channels. In $\beta$ wave, there was no significant difference in both channels.

\section{DISCUSSION}

Cognitive function and depression are reported to have high relevance. Decline of cognition in the elderly and severity of depression showed a significant correlation (Han et al., 2008; Kauppila et al., 2007). In the result of MMSE-KC, the average score was $18.85 \pm 2.163$ and after performing, the score was $19.08 \pm$ 2.308 , which showed a significant difference as there was an increase of 0.95 score compared to before performing the program. In addition, as a result of $\mathrm{ADL}$, before performing the program, average score was $13.80 \pm 1.795$ and after performing the program, average score was $15.75 \pm 1.832$, which showed a significant difference as there was an increase of 1.95 score compared to

Table 5. Change of brain wave (electroencephalogram)

\begin{tabular}{lccccl}
\hline Wave & Channel & Before & After & $t$ & $P$-value \\
\hline$\theta$ Wave & Ch1 & $0.3085 \pm 0.02254$ & $0.3025 \pm 0.02468$ & 1.092 & 0.289 \\
& Ch2 & $0.2915 \pm 0.02870$ & $0.2715 \pm 0.02418$ & 2.617 & $0.017^{*}$ \\
\multirow{2}{*}{$\alpha$ Wave } & Ch1 & $0.2855 \pm 0.07911$ & $0.3075 \pm 0.06766$ & -3.101 & $0.006^{*}$ \\
& Ch2 & $0.2915 \pm 0.07590$ & $0.3140 \pm 0.06785$ & -2.986 & $0.008^{*}$ \\
\multirow{2}{*}{$\beta$ Wave } & Ch1 & $0.2305 \pm 0.02328$ & $0.2400 \pm 0.03418$ & -1.246 & 0.228 \\
& Ch2 & $0.2305 \pm 0.03052$ & $0.2370 \pm 0.02812$ & -0.785 & 0.442 \\
\hline
\end{tabular}

Values are presented as mean \pm standard deviation $(\mu \mathrm{V})$.

${ }^{*} P<0.05$. 
before performing the program. The results showed much higher score difference than in improvement of cognitive function. Therefore, it was proved that exercise rehabilitation program for the elderly with mild dementia was effective for improving the performance capability of daily living activity.

Middleton et al. (2010) demonstrated that people who regularly exercised when they were young reduced the danger of cognitive disability more in the old age than those who did not exercise. In the study of 170 elderly who have problem in memory, aerobic exercise for 6 months significantly increased the cognitive function (Lautenschlager et al., 2008). As shown in animal experiment, exercise promoted the creation of nerve cell of dentate gyrus (Van Praag et al., 1999) and it increased the expression of nerve growth factors (Yu et al., 2006).

As a result of SGDS-K, average score before performing the program was $8.95 \pm 2.089$ and after performing the program was $8.85 \pm 2.207$ which showed a decreasing value of 0.1 compared to depression score before performing, but there was no statistically significant difference. Melancon et al. (2014) reported that acute aerobic exercise increased the effectiveness of plasma tryptophan in elderly and antidepressant effect was appeared due to the activation of sympathetic nerve during exercise. However, exercise rehabilitation program of fine motor movement for the elderly with mild dementia did not exert great effect on the decrease of depression. The study of Livingston et al. (2000) reported that physical disability and negative emotional reaction appeared to occur as depression and disturbance of daily living activity for the elderly. There was no statistically significant result on depression in this study, but there was an improvement of cognitive function and capability of daily living activity by exercise program of fin motor movement. We expect to have an effect on depression through participating in this exercise program long-term and regularly.

EEG wave represents the brain activity and has been used to measure brain function regardless of gender and age (Schreiter Gasser et al., 2008). $\theta$ wave is a slow wave that is noticeably increased in the old age and appeared often in occipital lobe and temporal lobe as dementia is processed (Lee and Kim, 2018). $\theta$ wave was increased in the elderly (Brassen and Adler, 2003). In the present results, $\theta$ wave was reduced after performing this exercise program. On the other hand, a wave is a basis for brain wave, and $\alpha$ wave reduced as dementia processed. Significant increase of $\alpha$ wave appeared after performing this exercise program. In contrast, there was no statistically significance in the $\beta$ wave after performing this exercise program, but increasing tendency appeared in this results. Especially $\beta$ wave is the brain wave that ap- pears when concentrating.

Through participating in this exercise program of fine motor movement, the elderly with mild dementia showed a significant improvement of cognitive function with daily living activity. As $\alpha$ wave reduced after performing this program, this exercise program showed effectiveness on dementia. The present study provides basic data for designing exercise rehabilitation program that can delay and relieve many physical and mental problems that the elderly can experience.

\section{CONFLICT OF INTEREST}

No potential conflict of interest relevant to this article was reported.

\section{ACKNOWLEDGMENTS}

This work was supported by the Ministry of Education of the Republic of Korea and the National Research Foundation of Korea (NRF-2016S1A5B6913737).

\section{REFERENCES}

Bae JN, Cho MJ. Development of the Korean version of the Geriatric Depression Scale and its short form among elderly psychiatric patients. J Psychosom Res 2004;57:297-305.

Brassen S, Adler G. Short-term effects of acetylcholinesterase inhibitor treatment on EEG and memory performance in Alzheimer patients: an open, controlled trial. Pharmacopsychiatry 2003;36:304-308.

Grieder M, Koenig T, Kinoshita T, Utsunomiya K, Wahlund LO, Dierks T, Nishida K. Discovering EEG resting state alterations of semantic dementia. Clin Neurophysiol 2016;127:2175-2181.

Han JH, Ko SK, Kweon JH, Jo IH, Ahn SM, Han CS, Park MH. Efficacy of a multifactorial cognitive ability enhancement program for MCI (Mild Cognitive Impairment) group. Korean J Clin Psychol 2008;27:805-821.

Han YR, Song MS, Lim JY. The effects of a cognitive enhancement group training program for community-dwelling elders. J Korean Acad Nurs 2010;40:724-735.

Howard MW, Rizzuto DS, Caplan JB, Madsen JR, Lisman J, Aschenbrenner-Scheibe R, Schulze-Bonhage A, Kahana MJ. Gamma oscillations correlate with working memory load in humans. Cereb Cortex 2003; 13:1369-1374.

Jhoo JH, Kim KW, Lee DY, Youn JC, Lee TJ, Choo IH, Ko HJ, Seo EH, Woo JI. Comparison of the performance in two different Korean Versions of Mini-Mental State Examination: MMSE-KC and K-MMSE. J 
Korean Neuropsychiatr Assoc 2005;44:98-104.

Kauppila T, Pesonen A, Tarkkila P, Rosenberg PH. Cognitive dysfunction and depression may decrease activities in daily life more strongly than pain in community-dwelling elderly adults living with persistent pain. Pain Pract 2007;7:241-247.

Ko KJ, Ha GC, Kang SJ. Effects of daily living occupational therapy and resistance exercise on the activities of daily living and muscular fitness in Guillain-Barré syndrome: a case study. J Phys Ther Sci 2017;29:950953.

Lautenschlager NT, Cox KL, Flicker L, Foster JK, van Bockxmeer FM, Xiao J, Greenop KR, Almeida OP. Effect of physical activity on cognitive function in older adults at risk for Alzheimer disease: a randomized trial. JAMA 2008;300:1027-1037.

Lee HJ, Kim KD. Effect of physical activity on cognition and daily living activities of the elderly with mild dementia. J Phys Ther Sci 2018; 30:428-433.

Livingston G, Watkin V, Milne B, Manela MV, Katona C. Who becomes depressed? The Islington community study of older people. J Affect Disord 2000;58:125-133.

Man DW, Tam SF, Hui-Chan C. Prediction of functional rehabilitation outcomes in clients with stroke. Brain Inj 2006;20:205-211.

Melancon MO, Lorrain D, Dionne IJ. Changes in markers of brain serotonin activity in response to chronic exercise in senior men. Appl Physiol Nutr Metab 2014;39:1250-1256.

Middleton LE, Barnes DE, Lui LY, Yaffe K. Physical activity over the life course and its association with cognitive performance and impairment in old age. J Am Geriatr Soc 2010;58:1322-1326.

Ministry of Health \& Welfare. Elderly stats [Internet]. Sejong: Ministry of Health \& Welfare; c2018 [cited 2018 Feb 20]. Available from: http:// www.bokjiro.go.kr/welInfo/retrieveWelInfoBoxList.do?searchIntClId=06.

Okumiya K, Matsubayashi K, Wada T, Kimura S, Doi Y, Ozawa T. Effects of exercise on neurobehavioral function in community-dwelling older people more than 75 years of age. J Am Geriatr Soc 1996;44:569-572.

Onofrj M, Thomas A, Iacono D, Luciano AL, Di Iorio A. The effects of a cholinesterase inhibitor are prominent in patients with fluctuating cognition: a part 3 study of the main mechanism of cholinesterase inhibitors in dementia. Clin Neuropharmacol 2003;26:239-251.

Oshida Y, Yamanouchi K, Hayamizu S, Sato Y. Long-term mild jogging increases insulin action despite no influence on body mass index or VO2 max. J Appl Physiol (1985) 1989;66:2206-2210.

Pugnetti L, Baglio F, Farina E, Alberoni M, Calabrese E, Gambini A, Di Bella E, Garegnani M, Deleonardis L, Nemni R. EEG evidence of posterior cortical disconnection in PD and related dementias. Int J Neurosci 2010;120:88-98.

Schreiter Gasser U, Rousson V, Hentschel F, Sattel H, Gasser T. Alzheimer disease versus mixed dementias: an EEG perspective. Clin Neurophysiol 2008;119:2255-2259.

Statistics Korea. Elderly stats [Internet]. Daejeon: Statistics Korea; [cited 2018 Feb 20]. Available from: http://kostat.go.kr/portal/eng/index.action.

Van Alphen HJ, Hortobágyi T, van Heuvelen MJ. Barriers, motivators, and facilitators of physical activity in dementia patients: a systematic review. Arch Gerontol Geriatr 2016;66:109-118.

Van Praag H, Christie BR, Sejnowski TJ, Gage FH. Running enhances neurogenesis, learning, and long-term potentiation in mice. Proc Natl Acad Sci U S A 1999;96:13427-13431.

Yoo S, Kim DH. Perceived urban neighborhood environment for physical activity of older adults in Seoul, Korea: a multimethod qualitative study. Prev Med 2017;103S:S90-98.

Yu F, Kolanowski AM, Strumpf NE, Eslinger PJ. Improving cognition and function through exercise intervention in Alzheimer's disease. J Nurs Scholarsh 2006;38:358-365. 